\title{
Steam Activated Carbon Preparation Using HTFBR from Biomass and its Adsorption Characteristics
}

\author{
Herbert Asirvatham J. ${ }^{1}$, Nikhar Gargieya ${ }^{2}$, Paradkar Manali Sunil ${ }^{2}$, \\ B.G. Prakash Kumar ${ }^{2, \uparrow}$ and Lima Rose Miranda ${ }^{1}$
}

\author{
${ }^{1}$ Carbon Research and Engineering Laboratory, Chemical Engineering Department, A. C. College of Technology, Anna University, Chennai-600025, India. \\ ${ }^{2}$ Chemical Engineering Department, BITS- PILANI, Dubai, P.Box 500022, UAE. \\ ‘e-mail:bgp_chemin@yahoo.com \\ (Received August 14, 2008; Accepted September 8, 2008)
}

\begin{abstract}
The objective of this work is to study the feasibility of the preparation of the activated carbon (AC) from coconut tree flowers using high temperature fluidized bed reactor (HTFBR). The activating agent used in this work is steam. The reactor was operated at various activation temperature $\left(650,700,750,800\right.$ and $\left.850^{\circ} \mathrm{C}\right)$ and activation time $(30,60,120$ and $240 \mathrm{~min})$ for the production of $\mathrm{AC}$ from coconut tree flowers. Effect of activation time and activation temperature on the quality of the AC preparation was observed. Prepared AC was characterized in-terms of iodine number, methylene blue number, methyl violet number, ethylene glycol mono ethyl ether (EGME) surface area and SEM photographs. The best quality of AC from coconut tree flowers (CFC) was obtained at an activation temperature and time of $850^{\circ} \mathrm{C}$ and $1 \mathrm{hr}$ restectively. The effectiveness of carbon prepared from coconut tree flowers in adsorbing crystal violet from aqueous solution has been studied as a function of agitation time, carbon dosage, and $\mathrm{pH}$. The adsorption of crystal violet onto AC followed second order kinetic model. Adsorption data were modeled using both Langmuir and Freundlich classical adsorption isotherms. The adsorption capacity $\mathrm{q}_{\mathrm{m}}$ was $277.78 \mathrm{mg} / \mathrm{g}$., equilibrium time was found to be $180 \mathrm{~min}$. This adsorbent from coconut tree flowers was found to be effective for the removal of CV dye.
\end{abstract}

Keywords : Activated carbon, High temperature fluidized bed reactor, Steam activation, Coconut tree flowers and adsorption

\section{Introduction}

Activated carbons (AC) are highly porous materials and are useful in processes as adsorbents for product purification and separation. Their versatility in use allows serving as catalysts and catalysts supports because of extensive surface area, high degree of surface reactivity and favorable pore size distribution [1]. Raw material for the production of $\mathrm{AC}$ should possess rich carbon content, though coal can be used as precursor for the production of $\mathrm{AC}$, biomass wastes may supersede the position of coal as precursor because of its cheapness, ease of availability and abundance in nature.

In the present work, a biowaste product coconut tree flowers has been used as the precursor. India is the third largest coconut producer in the world. After pollination, around $80 \%$ of male flowers are waste from a coconut tree. To enhance the value of this bio-waste preparation of $\mathrm{AC}$ has been attempted. Literature on production of $\mathrm{AC}$ from coconut tree flowers by chemical activation is very few [2,3] and by steam activation has not been attempted.

The methods of activation commonly employed are broadly divided into two main types, thermal or physical activation, and chemical activation. Thermal activation (between 600 and $1100^{\circ} \mathrm{C}$ ) is carried out in presence of oxidizing gases such as steam, $\mathrm{CO}_{2}$, air or any mixture of these gases. Steam treated samples have a basic character which is due to this kind of oxygen-containing groups and mainly to the electron rich oxygen-free sites located on the carbon basal planes. The final microstructure is dependent on raw material, heat treatment temperature and activation time [4].

The objective of the present work is to study influence of various parameters such as activation temperature, activation time on the preparation of coconut tree flowers carbon (CFC) using a high temperature fluidized bed reactor. Batch adsorption studies were carried out using the best quality CFC from the above method as adsorbent and crystal violet dye used as the adsorbate.

Crystal violet dye also known as gentian violet or hexamethyl pararosaniline chloride is use to control fungi and intestinal parasites in humans, as an antimicrobial agent on burn victims, to treat umbilical cords of infants, for the treatment of veterinary problems [5].

Fluidized bed technology is one of the most efficient and economic methods of actualizing pyrolysis, as it offers high heating rate, rapid devolatilization, convenient char collection, high degree of heat and mass transfer and effective temperature control [6]. Fluidized bed reactor has its own advantage than other reactors (packed bed reactor, shaft kilns 
Table 1. Proximate Analysis of Coconut Tree Flowers

\begin{tabular}{lc}
\hline Properties & Wt \% (Wet Basis) \\
\hline Fixed Carbon & 26.78 \\
Volatile matter & 61.52 \\
Moisture content & 6.73 \\
Ash content & 4.97 \\
\hline
\end{tabular}

and rotary kilns) for $\mathrm{AC}$ production. Other reactors affect pore structure and uniform creation of porous structure [7].

\section{Experimental}

\subsection{Coconut tree flowers - the precursor}

Coconut tree flowers which are having high carbon content meet the basic need of the precursor for the $\mathrm{AC}$ preparation. Its low density offer eases of fluidization. The proximate analysis of the precursor is shown in Table 1.

Though coconut tree flowers can be used for preparing ACs via $\mathrm{H}_{3} \mathrm{PO}_{4}, \mathrm{ZnCl}_{2}, \mathrm{HCl}$ etc. treatment, an environmental friendly steam activation method is preferred on account of the resultant secondary pollution and chemical consumption over chemical activation method.

\subsection{Apparatus}

Experimental setup (Fig. 1) consists of steam generator and a stainless steel column, which can withstand high operating temperature. Electrical heating of water generates steam. Steam generator consists of pressure gauge for pressure measurement, pressure relief valve and a safety valve. Stainless steel fluidizing column is heated by heating coils. For temperature measurements thermocouple is placed above the particles in the fluidized bed. Temperature measurements are relayed to the digital display in the panel. Thermostat is available to have good control over the operating temperature of the fluidized bed. The outlet of the steam generator is connected through a needle valve to the bottom of the fluidized bed reactor. To hold, the carbon particles grid is placed in the bottom of the reactor. Enough ceramic beads are also placed inside column between the bottom grid and the junction of steam pipe with the bed to ensure the uniform distribution of steam inside the bed and this assembly is called as steam distributor. Fluidized bed is well insulated with the glass wool and asbestos sheets from its surroundings to avoid the heat losses.

\subsection{Preparation of activated carbon by physical method}

Steam was used as an activating agent throughout the process. The preparation method is single stage process that is carbonization followed by activation, carried out in the HTFBR in one step.

Steam activation is endothermic in nature, so heat must be

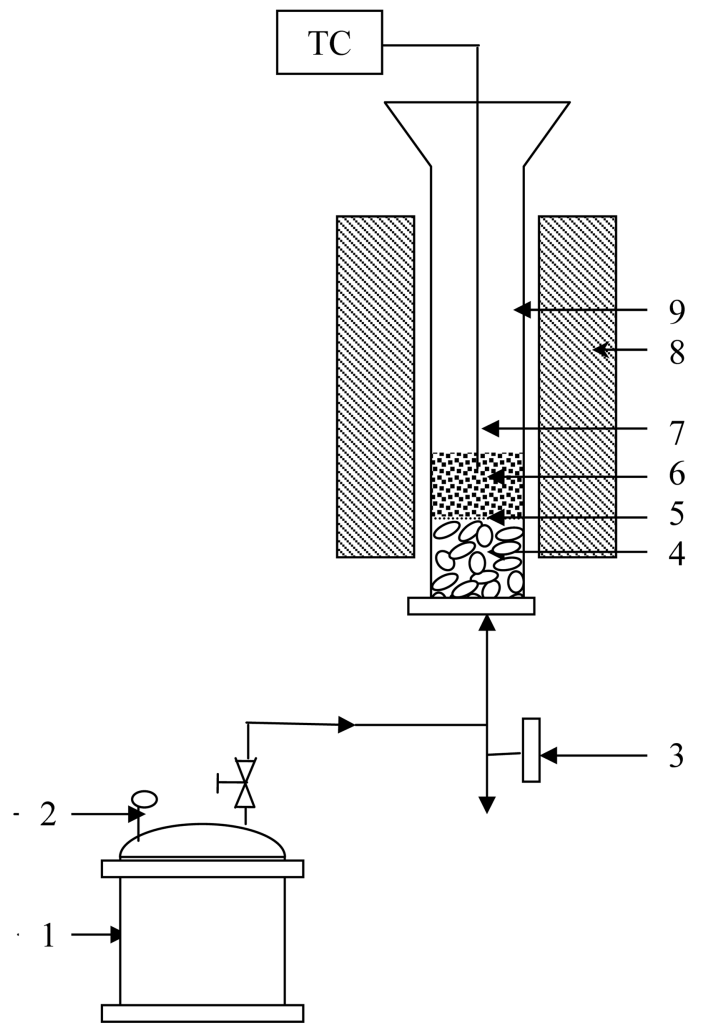

1. Steam generator

2. Pressure gauge

3. Steam trap

4. Ceramic beads

5. Bottom grid

6. Carbon

7. Thermocouple

8. Electric heater

9. Fluidized bed reactor

Fig. 1. Schematic representation of high temperature fluidized bed reactor. 
Table 2. Process Conditions of AC Preparation

\begin{tabular}{lc}
\hline Parameters & Conditions \\
\hline Fluidizing velocity ratio $\left(\mathrm{U} / \mathrm{U}_{\mathrm{mf}}\right)$ & $1.5-1.8$ \\
Activation temperature & $650-850^{\circ} \mathrm{C}$ \\
Activation time & $30-240 \mathrm{~min}$ \\
Operating pressure in steam generator & $1.5 \mathrm{~kg}_{\mathrm{f}} / \mathrm{cm}^{2}$ \\
\hline
\end{tabular}

supplied externally. Uniform heating of the fluidized material at the rate of $10^{\circ} \mathrm{C} / \mathrm{min}$ was ensured throughout the preparation process. Carbonization starts around $250^{\circ} \mathrm{C}$ and was followed till $600^{\circ} \mathrm{C}$. Carbonization offers initial removal of volatile matter from the precursor. The fluidizing medium steam was useful to create oxygen deficient atmosphere in the fluidized bed reactor during carbonization. Steam activation was carried out at various temperatures and for various activation times (Table 2).

\subsection{Characterization}

The iodine ( $\mathrm{mg}$ of iodine adsorbed/g of carbon) and methylene blue number ( $\mathrm{mg}$ of methylene blue adsorbed $/ \mathrm{g}$ of carbon) were determined according to ASTM 4607-86 and BIS 877-1977 standards, respectively. The burn-off weight percentage measures the degree of activation process. It is mathematically expressed as,

$$
\text { Percentage Burn-off }=\frac{\left(\mathrm{W}_{\mathrm{i}}-\mathrm{W}_{\mathrm{f}}\right)}{\mathrm{W}_{\mathrm{i}}} \times 100
$$

where $\mathrm{W}_{\mathrm{i}}$ is the initial weight of the raw material and $\mathrm{W}_{\mathrm{f}}$ is the final weight of product. The surface area of the AC was deduced by ethylene glycol mono ethyl ether (EGME) retention method $[8,9]$. The surface area was calculated from the following equation.

$$
\text { Surface area }=\frac{\mathrm{W}_{\mathrm{a}}}{0.000286 \mathrm{~W}_{\mathrm{s}}} \mathrm{m}^{2} / \mathrm{g}
$$

The surface morphologies of the AC were determined using scanning electron microscopy (NEO Stereo scan 440 scanning electron microscope, UK).

\subsection{Equilibrium studies}

Batch adsorption studies were performed at room temperature $\left(30 \pm 2^{\circ} \mathrm{C}\right)$ using $\mathrm{AC}$ prepared at $850^{\circ} \mathrm{C}$ from coconut tree flowers. $50 \mathrm{ml}$ of crystal violet dye with concentration $300 \mathrm{mg} / \mathrm{l}$ was taken in $250 \mathrm{ml}$ conical flasks containing different dosages of carbons viz 10, 20, 30, 35, 40, 45, 50, 55 and $60 \mathrm{mg}$. The flasks were agitated at room temperature at $180 \mathrm{rpm}$ for a pre-determined time until equilibrium was attained. Preliminary experiments have shown that the adsorption process attains equilibrium in $3 \mathrm{~h}$ (Fig. not shown) for the ACs in the present study. After attainment of equilibrium, dye concentrations in supernatant solution were estimated by measuring the absorbance at maximum wavelengths, $\lambda_{\max }$ of $582 \mathrm{~nm}$ for crystal violet using Hitachi UV-Visible spectrophotometer (U-2000). Studies on effect of $\mathrm{pH}$ were also made for $\mathrm{pH}$ varying from 2 to 11 and $\mathrm{pH}$ was adjusted to the desired value using $\mathrm{HCl}$ and $\mathrm{NaOH}$ solutions.

The equilibrium adsorption capacities $\left(\mathrm{q}_{\mathrm{e}}\right)$ of the $\mathrm{AC}$ at different solute concentrations were determined based on adsorbate mass balance using the following equation as,

$$
\mathrm{q}_{\mathrm{e}}=\frac{\left(\mathrm{C}_{\mathrm{o}}-\mathrm{C}_{\mathrm{e}}\right) \mathrm{V}}{\mathrm{m}}
$$

Where $\mathrm{q}_{\mathrm{e}}$ is the amount of dye adsorbed per gram of carbon $(\mathrm{mg} / \mathrm{g}), \mathrm{C}_{\mathrm{e}}$ is equilibrium concentration of the dye $(\mathrm{mg} / \mathrm{L}), \mathrm{C}_{\mathrm{o}}$ is initial concentration of the dye $(\mathrm{mg} / \mathrm{L})$ and $\mathrm{m}$ is the mass of the carbon taken $(\mathrm{g})$.

\section{Results and Discussion}

\subsection{Effect of activation temperature on preparation of $A C$}

High activation temperature leads to more microporous carbons than low activation temperatures. As activation temperature increases iodine number (IN), methylene blue number (MBN), methyl violet number (MVN) and burn off $\%$ (BO) increases (Fig. 2). Iodine number, methylene blue number and methyl violet number indicates the presence of micropores, initial phase of mesopores and well developed mesopores respectively in the prepared AC. Higher value of iodine number at higher activation temperature indicates the creation of microporous structure in the resulted AC. The action of steam is to play an important role during pyrolysis of the raw materials, it enhances supplementary volatiles evolution at lower temperatures, its continuous flow prevents thermal cracking of the volatile products as well as deposition of carbon on the solid phase, and it induces controlled gasification of the produced carbon skeleton [10].

A steady increase of MBN (Fig. 2) on increasing activation temperature is due to the rapid pore widening process.

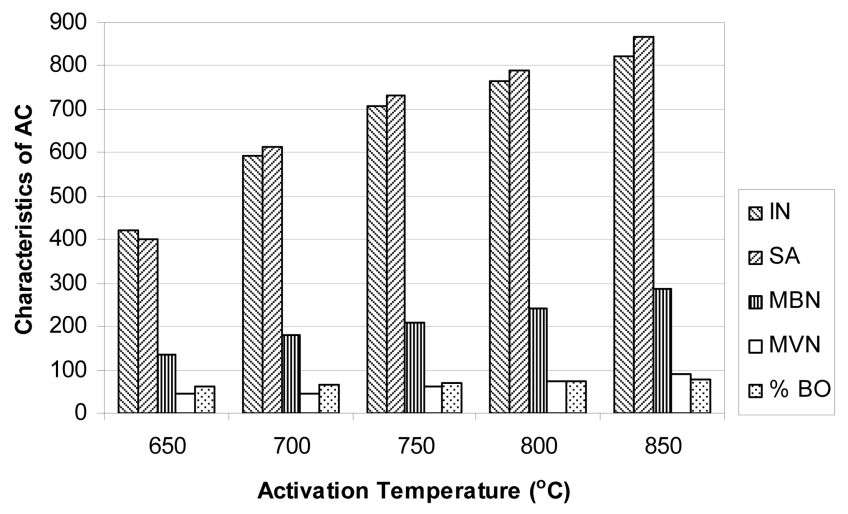

Fig. 2. Effect of activation temperature on IN, MBN, MVN, $\% \mathrm{BO}$ and $\mathrm{SA}$ for the activation time of $1 \mathrm{hr}$. 


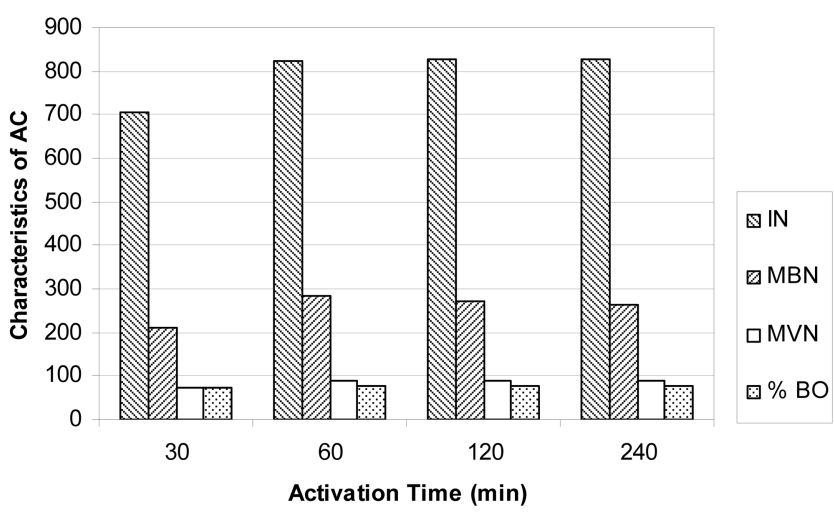

Fig. 3. Effect of activation time on $I N, M B N, M V N$ and $\% B O$ at the activation temperature of $850^{\circ} \mathrm{C}$.

From 650 to $700^{\circ} \mathrm{C}$ there is no increase in MVN was observed. After $700^{\circ} \mathrm{C}$ a steady increase of MVN is due to the fact that at lower activation temperature pore drilling is the dominant mechanism, thus increasing the diameter of pores near the mouth of the pores only. At lower temperature, the rudimentary pores resulted from carbonization facing terrible dearth for activating agent.

Increase in percentage burn-off indicates the decrease in the yield of $\mathrm{AC}$ as activation temperature increases (Fig. 2). Lower yield of AC under flow of steam is related to the ability of water vapor to penetrate the solid material and efficient removal of the volatile products from it. At later stages slow rate of burn-off was observed due to partial removal of carbon or removal of tarry materials.

\subsection{Effect of activation time on preparation of $A C$}

Residence time has a predominant influence on the porosity development during activation. Influence of the activation time on the development of the micropore volume is interesting from Fig. 3. By increasing activation time from $30 \mathrm{~min}$ to $60 \mathrm{~min}$ rapid increase in the $\mathrm{IN}$ (micropore development) up to one hour is possibly due to the opening of restricted pores, whereas further treatment results in minor changes in micropore development.

Increasing activation time increases $\mathrm{MBN}$ and $\mathrm{MVN}$ number till one-hour activation period (Fig. 3). Beyond activation time of one hour there is no significant change in MVN and slight drop in MBN. So, for the production of AC activation time of $2 \mathrm{hr}$ or greater is not helpful for creation of further pore development. Though transformation of micropores to mesopores is expected, there may be possibility of the transformation of well developed meso- pores into initial stages of mesopores due to the shrinkage at higher activation temperature and activation time [7].

At higher activation temperature of $850^{\circ} \mathrm{C}$ and increasing the activation time effective destruction takes place at increasing burn-off following shrinking core behaviour or shrinkage of carbon. This is due to higher removal of substances resulted by the carbonization during the initial stages (Fig. 3). This is in well agreement with results Lua and Guo [11], they concluded that most of the volatile matter might have been released during the initial staged of activation before reaching the final activation temperature.

Other parameter like operating velocity ratio $\left(\mathrm{U} / \mathrm{U}_{\mathrm{mf}}\right)$ seems to have no significant effect on AC preparation in HTFBR. This was already confirmed by various authors
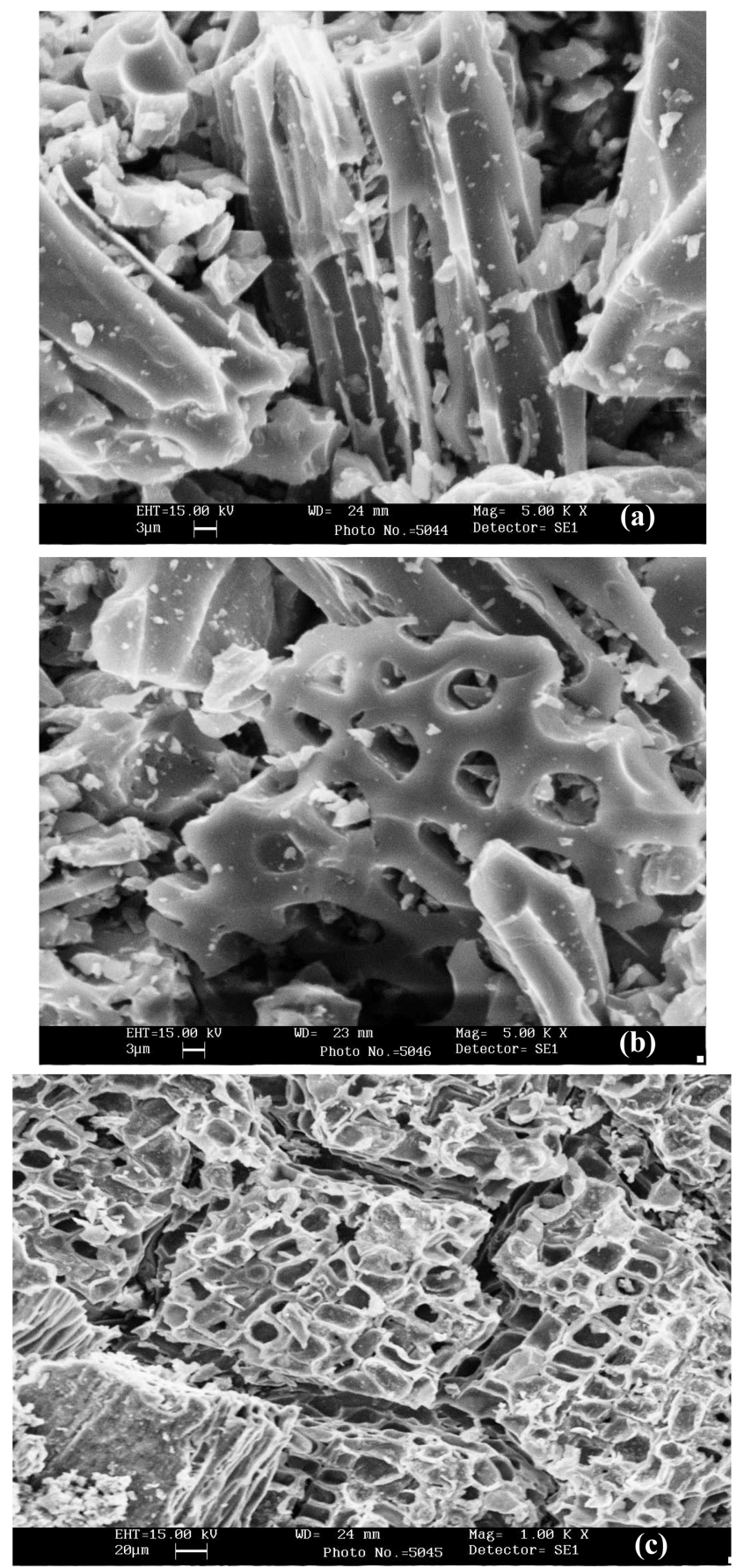

Fig. 4. (a) and (b) SEM photographs of CFC prepared at $850^{\circ} \mathrm{C}$, and (c) SEM photographs of CFC prepared at $650^{\circ} \mathrm{C}$. 
Table 3. Adsorption Constants for the Sorption of Crystal Violet Dye on AC

\begin{tabular}{|c|c|c|c|c|c|c|c|}
\hline \multirow{3}{*}{$\begin{array}{c}\text { AC prepared } \\
\text { at } 850^{\circ} \mathrm{C}\end{array}$} & \multicolumn{3}{|c|}{ Freundlich } & \multicolumn{4}{|c|}{ Langmuir } \\
\hline & $\overline{\mathrm{K}_{\mathrm{F}}(\mathrm{mg} / \mathrm{g})(\mathrm{g} / \mathrm{L})^{\mathrm{n}}}$ & $\mathrm{n}$ & $\mathrm{R}^{2}$ & $\mathrm{q}_{\mathrm{m}}(\mathrm{mg} / \mathrm{g})$ & $\mathrm{K}_{\mathrm{L}}(\mathrm{L} / \mathrm{mg})$ & $\mathrm{R}_{\mathrm{L}}$ & $\mathrm{R}^{2}$ \\
\hline & 238.34 & 33.67 & 0.85 & 277.78 & 2.0 & 0.002 & 0.997 \\
\hline
\end{tabular}

Table 4. Adsorption Kinetic Model Constants for the Crystal Violet on AC

\begin{tabular}{ccccccc}
\hline AC prepared & \multicolumn{3}{c}{ First Order } \\
\cline { 2 - 7 } at $850^{\circ} \mathrm{C}$ as & $\mathrm{q}_{\mathrm{e}}(\mathrm{exp})(\mathrm{mg} / \mathrm{g})$ & $\mathrm{K}_{1}(\mathrm{~min})^{-1}$ & $\mathrm{q}_{\mathrm{e}}(\mathrm{calc})(\mathrm{mg} / \mathrm{g})$ & $\mathrm{R}^{2}$ & $\mathrm{~K}_{2}(\mathrm{~g} / \mathrm{mgmin})\left(\times 10^{3}\right) \mathrm{q}_{\mathrm{e}}($ calc $)(\mathrm{mg} / \mathrm{g})$ & $\mathrm{R}^{2}$ \\
adsorbent & 363 & 0.0122 & 26 & 0.836 & 1.69 & 370 \\
\hline
\end{tabular}

$[9,12,13]$.

\subsection{Scanning electron microscope images (SEM)}

SEM images of the prepared ACs were taken to visualize and to ensure the development of porosity. SEM photographs were taken for the AC prepared from coconut tree flowers prepared at $850^{\circ} \mathrm{C}$ (Fig. 4 a, b) and $650^{\circ} \mathrm{C}$ (Fig. 4 c) at one-hour activation time. Photographs were taken at $1000 \times$, and $5000 \times$ magnifications. Soft material gives fibrillar structure and hard woody material gives cross inter connected pores in nature. It was observed that the $\mathrm{AC}$ has well smooth surface areas with long ridges, resembling a series of parallel lines. The straight tubes each with nearly uniform dimensions are noticed in these figures. It is evident from the figures that the pore development plays a vital role as increasing the activation temperature.

\subsection{Surface area}

Increase in activation temperature increases the surface area. This indicates that surface area development is also a function of the activation temperature and the highest surface area is $866 \mathrm{~m}^{2} / \mathrm{g}$ obtained at $850^{\circ} \mathrm{C}$.

\subsection{Adsorption studies}

Rate of adsorption is closely related to the porosity and surface reactivity of AC. A simple and effective representation of the adsorption behavior of prepared AC is represented by using Langmuir and Freundlich models [14]. Linear form of Freundlich isotherm is,

$$
\log \mathrm{q}_{\mathrm{e}}=\log \mathrm{K}_{\mathrm{F}}+(1 / \mathrm{n}) \log \mathrm{C}_{\mathrm{e}}
$$

Equilibrium relationships between adsorbent and adsorbate can be described by adsorption isotherms. The capacity of $\mathrm{AC}$ for a given pollutant is usually determined by carrying out an adsorption isotherm. Linear form of Langmuir isotherm is,

$$
\frac{\mathrm{C}_{\mathrm{e}}}{\mathrm{q}_{\mathrm{e}}}=\frac{1}{\mathrm{q}_{\mathrm{m}} \mathrm{K}_{\mathrm{L}}}+\frac{\mathrm{C}_{\mathrm{e}}}{\mathrm{q}_{\mathrm{m}}}
$$

From the Fig. 5 it is obvious that Langmuir fitted the experimental results well than Freundlich Isotherm [15]. This is also confirmed from the $\mathrm{R}^{2}$ value in Table 3 .

The kinetics of the adsorption was evaluated from the batch equilibrium data using pseudo-first order and pseudosecond order kinetic models in order to understand the dynamics of adsorption process [9]. The equations are:

$$
\begin{aligned}
& \log \left(q_{e}-q\right)=\log q_{e}-K_{l} t / 2.303 \\
& t / q=\left(1 / K_{2} q_{e}^{2}\right)+t / q_{e}
\end{aligned}
$$

where $\mathrm{q}$ is the amount of dye adsorbed at time $\mathrm{t}\left(\mathrm{mg} \mathrm{g}^{-1}\right), \mathrm{K}_{1}$ $\left(\mathrm{min}^{-1}\right)$ and $\left.\mathrm{K}_{2}\left(\mathrm{~g} \mathrm{mg}^{-1} \mathrm{~min}^{-1}\right)\right)$ are rate constants of Lagergren and second order rate equations respectively. The adsorption rate constants are presented in Table 4 . The results show that the second order rate equation fitted the experimental $\mathrm{q}_{\mathrm{e}}$ data better when compared to the first order equation (Fig. 6). The uptake capacity of CFC for CV dye was found to be $363 \mathrm{mg} \mathrm{g}^{-1}$ respectively. The results showed that the performance of carbon produced in the present study was much better when compared to the results reported by Senthilkumaar et al. (2006) for the adsorption of CV on to coconut tree flowers $\left(85.84 \mathrm{mg} \mathrm{g}^{-1}\right)$ by chemical activation methods.

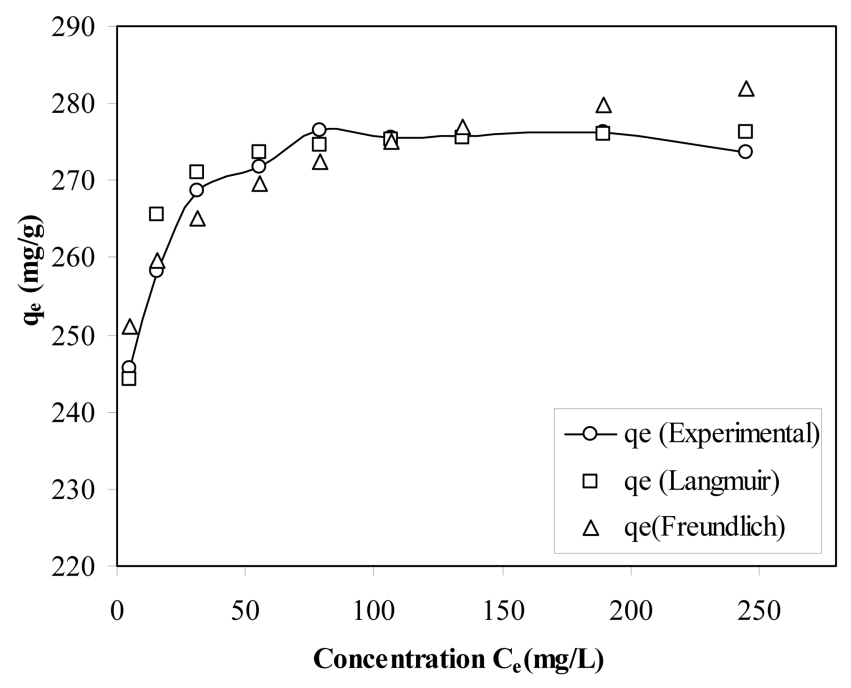

Fig. 5. Typical plot of comparison between the experimental and modelled concentration profiles for adsorption of $\mathrm{CV}$ dye on CFC. 


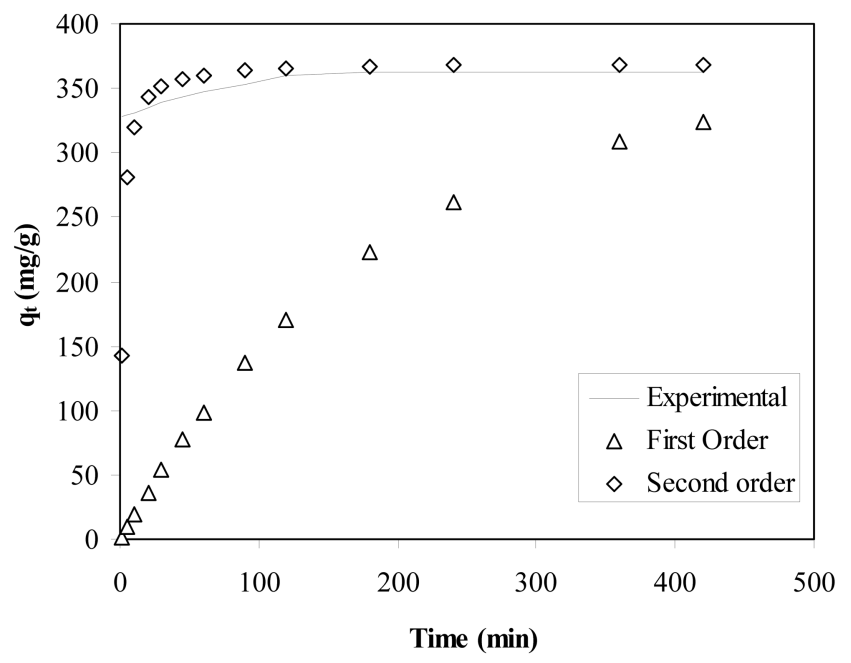

Fig. 6. Typical plot of comparison between the experimental and modeled time profiles for adsorption of CV dye on CFC.

The $\mathrm{pH}$ of solution from which adsorption occurs may influence the extent of adsorption. Decreasing the $\mathrm{pH}$ of the dye solution from 11 to 2 , the percent removal increases from 72 to $77 \%$ for the dye (Fig. 7). Lower adsorption of crystal violet dye at acidic $\mathrm{pH}$ is due to the presence of excess $\mathrm{H}^{+}$ions inhibiting the adsorption sites. When solution $\mathrm{pH}$ is lower than natural $\mathrm{pH}$, the adsorbent surface and dye molecules both are highly in protonated form hence, there is electrostatic repulsion between dye and protonated adsorbent surface which leads to lower removal of dye [16]. Increasing solution $\mathrm{pH}$ increases the number of hydroxyl groups, thus increasing the number of negatively charge sites and thereby increasing the attraction between dye and adsorbent surface $[17,18]$.

The intraparticle diffusion model presented here refers to the theory proposed by Weber and Morris [19], who

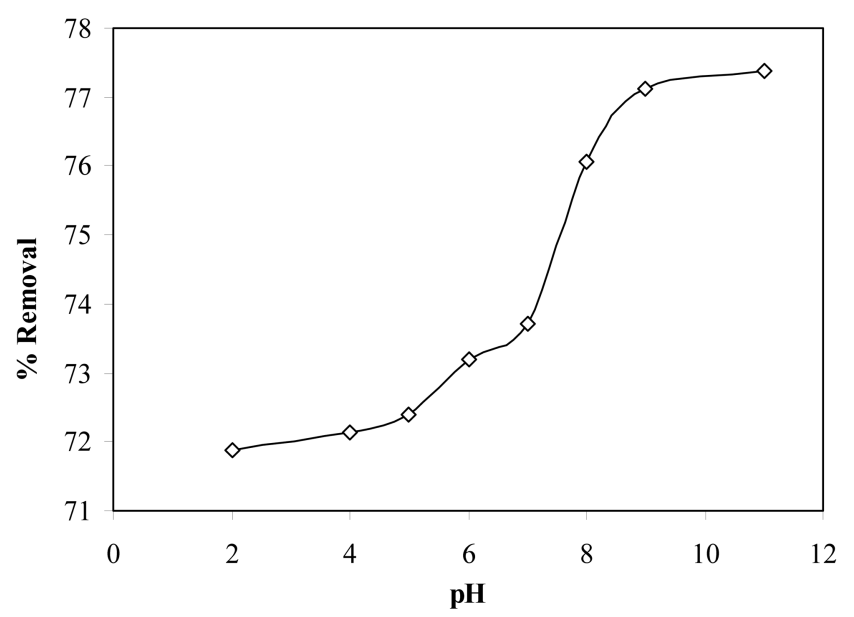

Fig. 7. Effect of system $\mathrm{pH}$ on adsorption crystal violet onto CFC.

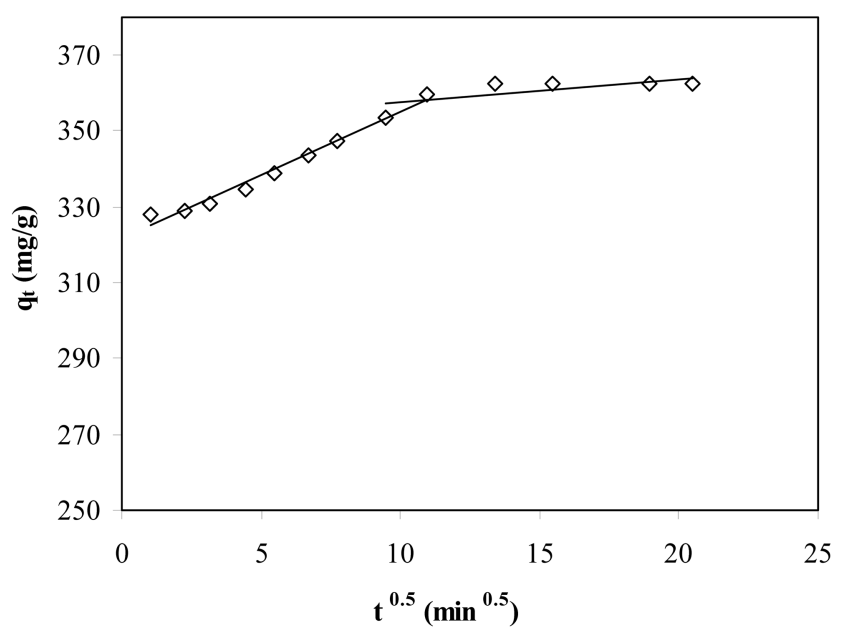

Fig. 8. Plot of intraparticle diffusion model for the adsorption of $\mathrm{CV}$ onto $\mathrm{CFC}$.

concluded that the uptake is proportional to the square root of contact time during the course of adsorption. Accordingly,

$$
\mathrm{q}_{\mathrm{t}}=\mathrm{k}_{\mathrm{p}}(\mathrm{t})^{0.5}
$$

Where $\mathrm{k}_{\mathrm{p}}\left(\mathrm{mg} / \mathrm{gmin}^{0.5}\right)$ is the rate constant of intraparticle transport. The initial curved portion relates the boundary layer diffusion and the latter linear portion represents the intraparticle diffusion. From Fig. 8, it may be observed that the straight line did not pass through the origin and this further indicates that the intraparticle diffusion is not only the rate-controlling step. The adsorption data indicate that the removal of crystal violet dye from aqueous solution is rather complex process involving both boundary layer diffusion and intraparticle diffusion. $\mathrm{D}_{\mathrm{i}}$ is calculated from the slope of the plot of $\ln \left(1-\mathrm{q}_{\mathrm{t}} / \mathrm{q}_{\mathrm{e}}\right)$ versus $\mathrm{t}$ (Fig. not shown). The value of $\mathrm{D}_{\mathrm{i}}$ is found to be $3.96 \times 10^{14} \mathrm{~m}^{2} / \mathrm{s}$. If intraparticle or pore diffusion is to be the rate limiting step the diffusion coefficient should be in the range of $10^{-12}$ to $10^{-14} \mathrm{~m}^{2} / \mathrm{s}$.

\section{Conclusions}

Waste male flowers of coconut tree were physically (steam) activated to non-toxic carbonaceous material. AC having iodine number of $824 \mathrm{mg} / \mathrm{g}$, methylene blue number of $285 \mathrm{mg} / \mathrm{g}$, methyl violet number of $90 \mathrm{mg} / \mathrm{g}$ and EGME surface area of $866 \mathrm{~m}^{2} / \mathrm{g}$ was obtained using operating conditions of $850^{\circ} \mathrm{C}$ and activation time of one hour using HTFBR. At higher activation temperature diffusion rate of activating agent is high and the higher temperature favours the endothermic reaction thus formation of pore development. Though transformation of micropores to mesopores may takes place, generation of many new pores confirms constant value of iodine number (micropores) in the $\mathrm{AC}$ at higher activation temperature. Higher value methylene blue 
and methyl violet upto activation time of one hour concludes the meso and macropores in the resulted AC. Transformation of mesopores to macro pores is confirmed by increasing the activation time period. Further, EGME surface area of 866 $\mathrm{m}^{2} / \mathrm{g}$ and SEM images of AC prepared at $850^{\circ} \mathrm{C}$ and activation time of one hour confirms the good porosity development. Diffusion controlled shrinking core type burnoff model follows preparation of AC in HTFBR. This means that mass transfer is controlling the preparation process of $\mathrm{AC}$ from coconut tree flowers under operating conditions of HTFBR.

The adsorption of crystal violet dye on AC fitted well for Langmuir isotherm than Freundlich isotherm. The kinetics of the adsorption of a basic dye, crystal violet onto the carbons follows pseudo second order kinetics. The value of $\mathrm{D}_{\mathrm{i}}$ is found to be $3.96 \times 10^{14} \mathrm{~m}^{2} / \mathrm{s}$ this confirms the diffusion controlling adsorption of crystal violet on AC.

The present study on preparation of AC from coconut tree flowers by steam activation shows the activation process would add value to these agricultural commodities as effective adsorbents. Henceforth coconut tree flowers can be viewed as good precursor for AC preparation.

\section{References}

[1] Bansal, R. C.; Donnet, J. B.; Stoeckli, H. F. “Active carbon", Marcel Dekker Publisher, New York, 1988.

[2] Senthilkumaar, S.; Kalaamani, P.; Porkodi, K.; Varadarajan, P. R.; Subburaam, C. V. Bioresource Technol. 2006, 97, 1618.
[3] Senthilkumaar, S.; Kalaamani, P.; Subburaam, C. V. J. Hazard. Mater. 2006, 136, 800.

[4] Smisek, M.; Cerny, S. "Active Carbon - Manufacture, Properties and Applications", Elsevier Publisher, Amsterdam, 1970.

[5] Afaík, I.; Afaíková, M. Water Res. 2002, 36, 196.

[6] Min, A.; Harris, A. T. Chem. Eng. Sci. 2006, 61, 8050.

[7] Wigmans, T. Carbon. 1989, 27, 13.

[8] Cerato, A. B.; Lutenegger, A. J. Geotech. Testing. 2002, 25, 1.

[9] Prakash Kumar, B. G.; Shivakamy, K.; Lima Rose Miranda; Velan, M. J. Hazard. Mater. 2006, 136, 922.

[10] Alaya, M. N.; Girgis, B. S.; Mourad, W. E. J. Porous Mat. 2000, 7, 509.

[11] Aik Chong Lua; Jia Guo. Carbon. 1998, 36, 1663.

[12] Kirubakaran, C.; Krishnaiah, K.; Seshadri, S. K. Ind. Eng. Chem. Res. 1991, 30, 2411.

[13] Al-Khalid, T. T.; Haimour, N. M.; Sayed S.A.; Akash, B. A. Fuel process. Technol. 1998, 57, 55.

[14] Selhan Karagöz, A.; Turgay Tay, B.; Suat Ucar, A.; Murat Erdem. Bioresource Technol. 2008, 99, 6214.

[15] Ghazy, S. E.; EI-Morsy, S. M., Carbon Lett. 2007, 8, 191.

[16] Namasivayam, C.; Kadirvelu, K. Bioresource Technol. 1994, 48, 79.

[17] Kadirvelu, K.; Thamaraiselvi, K.; Namasivayam, C. Sep. Purif. Technol. 2001, 24, 497.

[18] Kadirvelu, K.; Kavipriya, M.; Karthika, C.; Radhika, M.; Vennilamani, N.; Pattabhi, S. Bioresource Technol. 2003, 87, 129.

[19] Weber, W. J.; Morris, J. C. J. San. Eng. Div. ASCE. 1963, 89,31 . 